\title{
Orientação de mestrandos e doutorandos como atividade profissional
}

\author{
Thesis supervision as professional work
}

\author{
Orientación de maestría y doctorado como \\ actividad profesional
}

Neste texto, pretende-se estabelecer um diálogo com professores e pesquisadores que orientam estudantes de graduação e pós-graduação sobre temas relacionados à saúde. No entanto, antes de adentrar a especificidade da supervisão relacionada ao tema, considera-se importante discutir, de forma introdutória, sobre o que é orientar e sobre o que esperar de um orientador e de um orientando.

Há três premissas básicas nesta discussão. A primeira: orientação é inter-relação entre uma pessoa mais experiente academicamente - não um sabe-tudo - e um estudante que dá início ou continuidade à carreira de pesquisador ${ }^{1}$. Ela pode e deve ocorrer, de forma complementar, em sessões grupais 2 , em que professores, orientadores e colegas discutem em conjunto o tema de um estudante. Na Escola Nacional de Saúde Pública Sergio Arouca, Fundação Oswaldo Cruz, por exemplo, essas sessões se denominam "seminários avançados de dissertação e tese". Embora essa modalidade seja importante, particularmente por permitir uma socialização dos objetos e das angústias pessoais, esse segundo formato precisa ser muito bem desenhado para não se transformar em um momento de palpites que podem desorientar mais que colaborar com o estudante. A segunda premissa é a seguinte: sendo um ato técnico-profissional, orientar é também uma arte carregada de sentido humano e requer cuidados e precauções. A terceira: nos estágios de elaboração de monografias, dissertações e teses, as pessoas já se encontram nos níveis mais elevados de sua formação educacional. Portanto, o estudante que acorre a um professor ou pesquisador para ser orientado já é uma pessoa com bagagem acadêmica, conhecimentos e experiências que devem ser reconhecidos e compartilhados, por mais famoso que seja seu supervisor.

Embora fosse justo dissertar a respeito da díade orientador/orientando, esta introdução enfatiza o papel do orientador e utiliza questões trazidas por estudantes apenas para ilustrar os questionamentos sobre essa tarefa acadêmica de crucial importância para as instituições e a sociedade. Considera-se, pois, de um lado, que a orientação deve ser abordada como uma atividade exercida por "professores-pesquisadores" no cumprimento de sua agenda acadêmica e, por isso, recebem créditos 3,4. De outro, ela precisa ser tratada pelos que a exercem como o encontro entre dois seres humanos inteligentes que podem se complementar. Entre eles pode haver maior ou menor empatia, mas nunca falta de respeito e de compromisso que prejudiquem a construção de conhecimentos ou a saúde mental de ambos, particularmente da parte mais fraca, que é o estudante.

Existe hoje uma vasta literatura internacional que trata a orientação como um trabalho profissional multifacetado e como uma das mais complexas e importantes tarefas acadêmicas 1,4,5,6,7,8,9,10. Segundo os muitos autores consultados para a elaboração deste texto, a orientação é reconhecida
1 Escola Nacional de Saúde Pública Sergio Arouca, Fundação Oswaldo Cruz, Rio de Janeiro, Brasil.

\section{Correspondência}

M. C. S. Minayo Escola Nacional de Saúde Pública Sergio Arouca, Fundação Oswaldo Cruz. Av. Brasil 4036, sala 700, Rio de Janeiro, $R J$ 21040-361, Brasil. maminayo@terra.com.br 
como algo crucial para o sucesso de um programa acadêmico 7,11,12,13 e para a reputação institucional. Ela traz repercussões para seu prestígio e sua viabilidade financeira. Por causa da significância dessa nobre tarefa educativa, o trabalho de um orientador como um profissional de ensino de alto nível se tornou objeto de preocupação internacional, como se observa nos documentos da Organização para a Cooperação e Desenvolvimento Econômico (OCDE) 5; do Banco Mundial, o que fica patente no trabalho de Altbach \& Salmi 3; e da Associação de Universidades Europeias 8. Em todas essas organizações, à orientação de mestres e doutores (particularmente de doutores) é atribuído elevado valor social e político. A ideia por trás dessa valorização é o produto final da supervisão: pessoas suficiente e adequadamente treinadas, competentes e inteligentes emocionalmente, capazes de liderar o desenvolvimento de seus países.

No Brasil, apesar de alguns trabalhos sobre o tema, como é o caso do estudo de Diniz 14, a orientação acadêmica é ainda tratada de forma amadora, como uma aprendizagem que ocorre a partir da experiência e como algo de interesse privado de um professor com seu aluno. Assim, embora as monografias, dissertações e, em particular, as teses de doutorado devessem ter a maior atenção pedagógica possível, por serem as ações mais decisivas no processo educativo de alto nível, muitos estudantes não recebem o adequado monitoramento e o suporte estrutural e subjetivo necessários 10,15,16,17.

Prova da pouca atenção que o tema da orientação recebe se encontra no blogue Eu Confesso (Odeio Meu Orientador) 18, um espaço informal que corre e se multiplica na Internet. Nele há incontáveis desabafos de orientandos e de profissionais que terminaram sua formação. Esses depoimentos trazem informações sobre o que deve ou não fazer esse personagem tão fundamental para o país, o orientador, assim como a instituição que o abriga. De que falam os orientandos - alguns constrangidos, outros apavorados, outros irritados, outros até deprimidos - sobre essa interação? Resumidamente, as principais queixas dizem respeito (a) à arrogância; (b) ao menosprezo; (c) à irresponsabilidade; (d) à impaciência; (c), ao "pegar no pé”; e (d) ao "não estar nem aí", ou seja, ao descompromisso. Todas essas situações largamente explicitadas na internet dizem respeito a uma das expressões de violência mais dolorosas nas relações humanas: o assédio moral. Se "o pegar no pé" faz sofrer por excesso de exigências e ordens, o descompromisso deixa o estudante sem parâmetros para seguir em suas buscas, frequentemente chegando ao final do processo cheio de insegurança e aquém do que poderia alcançar.

Entre os depoimentos de estudantes, repete-se algo já bastante conhecido do mundo acadêmico brasileiro: situações de irresponsabilidade explícita em que o orientador corrige seu aluno durante a cerimônia de defesa da sua monografia, dissertação ou tese, evidenciando publicamente que não se envolveu e nem considerou a orientação como um trabalho acadêmico sério: faltou-lhe profissionalismo. Um dos problemas por trás das queixas dos estudantes - é claro, além dos arroubos de temperamento e da falta de polidez que podem ser mútuos nessa díade - é a dificuldade criada pela tradição acadêmica brasileira para estruturar essa relação: o orientador frequentemente é exposto como alguém que tem total poder sobre o orientando, havendo inclusive a chance de este ser retirado de um curso, por obra e graça da decisão de seu supervisor. Nos blogues, os estudantes se queixam de que são poucos os canais de expressão para o corpo discente dentro dos programas, o que cria dificuldades, por exemplo, para troca de orientador.

Vários trabalhos aqui citados 4,6,9,11,19 desenham o perfil do orientador como um profissional da educação em seu mais alto nível, ressaltando cinco exigências básicas a seu respeito: (1) que seja capaz de fazer uma aliança de aprendizagem para trabalhar com o estudante em objetivos comuns; (2) que esteja interessado no objeto da tese, dissertação ou monografia, aprendendo junto, compartilhando conhecimentos e agindo com sabedoria; (3) que tenha capacidade teórica e reflexiva comprovada por pesquisas, publicações, avaliação de artigos, de cursos e de programas acadêmicos; (4) que tenha clareza sobre as competências que o estudante precisa desenvolver, particularmente, a capacidade de escrever, falar e se comunicar sobre o objeto e sobre questões estudadas no seu curso. No caso das monografias, dissertações e teses da área de Saúde, acrescente-se a capacidade de transformar sua pesquisa em conhecimento prático ou para a prática; e (5) de grande importância, que tenha uma visão abrangente da realidade, colocando em perspectiva a importância do trabalho que está supervisionando e da pessoa que está orientando.

Sobre a inter-relação de orientação, a partir dos estudos citados e da experiência da autora deste trabalho, sugerem-se os seguintes pontos a um jovem orientador: (1) não subordine seu orientando e não o trate como se fosse uma "tabula rasa"; (2) ajude-o a delimitar a pergunta que direcionará seu pro- 
jeto de pesquisa; (3) uma vez escolhida a indagação inicial e norteadora, incentive-o a fazer uma boa revisão bibliográfica sobre o assunto e, se possível, dê-lhe dicas sobre leituras seminais, inspiradoras e sugestivas; (4) marque encontros periódicos com seu orientando, sempre mediante textos escritos que lhe sejam enviados previamente: apenas conversar sobre um tema não ajuda seu desenvolvimento e nem o enfrentamento das dificuldades acadêmicas; (5) tenha compromissos com os encontros marcados: seja pontual, nunca menospreze o tempo e a agenda do seu estudante, embora seja compreensível que haja necessidade de flexibilizá-la; (6) seja muito franco e claro quanto à qualidade dos trabalhos ou das etapas da pesquisa que seu orientando the apresentar e, caso necessário, ajude-o a melhorá-los; (7) estabeleça prazos e limites para cada etapa do desenvolvimento da tese, dissertação ou monografia e, quando preciso, seja exigente em relação ao que for combinado entre ambos; (8) procure antecipar problemas, chamando atenção sobre os riscos de incompetência acadêmica que vislumbra, a partir de sua experiência; (9) reconheça sua capacidade, mas também suas fraquezas e limitações e, se for necessário, peça ajuda de outro colega como coorientador para conduzir o trabalho a bom termo; por fim, (10) como resultado dessa interação, o mais desejável é que haja um crescimento mútuo e, mais que isso, uma continuidade da relação profissional em linhas de pesquisa, em apoios técnicos, em publicações e em outros compromissos acadêmicos.

É preciso deixar claro também o que um estudante não pode esperar do seu orientador: (1) que ele seja um terapeuta para tratar de suas crises emocionais; (2) que saiba responder a todas as perguntas; (3) que resolva os problemas de seu trabalho ou assuma compromissos no seu lugar; (4) que fique impassível ao receber rascunhos ou apontamentos em vez de textos coerentes; (5) que aceite seus atrasos e inadimplências em face dos encontros marcados, sem reagir; (6) que seja o revisor dos textos que recebe (embora esse último item sempre acabe acontecendo).

Enfim, este texto introdutório abre caminho para uma reflexão que precisa ser aprofundada em relação aos objetos específicos da orientação. Ela pode ser provisoriamente concluída pela afirmação de que a orientação é uma atividade profissional e relacional em que o orientando, pedagogicamente, deve ser reconhecido como produtor e participante ativo de conhecimento. Caso contrário, a tarefa do orientador se torna um ato de violência intersubjetiva. No momento histórico contemporâneo, esse trabalho profissional é de uma responsabilidade incontestável, pois ele repercute no desenvolvimento intelectual, cultural, social e econômico não só dos orientandos, mas também do país.

Embora este pequeno artigo possa ser apropriado por orientadores de qualquer área do conhecimento, é relevante fazer uma inflexão sobre os que atuam profissionalmente na área de ensino em Saúde Pública. Esses têm, pelo menos, dois desafios específicos. O primeiro é quanto à multidisciplinaridade que caracteriza os estudantes dos cursos de pós-graduação. Muitos vêm das áreas de Ciências Sociais, Economia, Estatística, Medicina, Enfermagem, Psicologia, até Segurança Pública, dentre outras. Esses alunos, que enriquecem os cursos com sua diversidade de saberes, não têm uma formação básica em Saúde Pública. Portanto, é imperioso que adquiram um corpo de conhecimentos e práticas, nela historicamente construídos. Embora seja tarefa da grade curricular propiciar a iniciação e o aprofundamento dos temas disciplinares centrais, ao orientador cabe avaliar e exigir de seus orientandos uma proficiência no campo no qual se diplomarão. Infelizmente, há muitas queixas não documentadas de que pessoas se formam sem saber os pilares teóricos e metodológicos da saúde coletiva.

O segundo desafio dos orientadores de mestrado e doutorado em Saúde Pública/Saúde Coletiva é a articulação entre teoria e prática. A área em pauta tem uma vocação inegável para produzir reflexões teórico-conceituais, metodológicas e técnicas que dialogam com os serviços e com as políticas: por meio de diagnósticos epidemiológicos, por meio de estudos qualitativos com os diversos atores que compõem o Sistema de Saúde ou ainda por meio de planejamento e programação da gestão dos serviços. Essa vocação da Pós-graduação em Saúde Coletiva a configura como estratégica para o desenvolvimento da população brasileira, de tecnologias e insumos para os serviços e de avaliação do desempenho do sistema em seus diversos componentes.

Sem dúvida, mestres e doutores que concluem dissertaçoes e teses brilhantes são a melhor propaganda de qualquer programa de pós-graduação. E no caso da saúde coletiva, o peso e o regozijo desse êxito são maiores quando se observam ex-alunos como ministros, secretários de saúde, gestores e profissionais de serviços competentes e comprometidos com temas de extrema relevância para $o$ bem-estar e a qualidade de vida da população brasileira. 


\section{Informação adicional}

ORCID: Maria Cecília de Souza Minayo (00000001-6187-9301).

1. Boeren E, Lokhtina-Antoniou I, Sakurai Y, Herman C, McAlpine L. Monitoring: review of early career researcher studies. Frontline Learning Research 2015; 3:68-80.

2. Dysthe O, Samara A, Westrheim, K. Multivoiced supervision of Master's students: a case study of alternative supervision practices in higher education. Studies in Higher Education 2006; 31:299-318.

3. Altbach PG, Salmi J, editor. The road to academic excellence. The making of world-class research universities. http://documents.world bank.org/curated/en/584591468324279676/ The-road-to-academic-excellence-the-mak ing-of-world-class-research-universities (acessado em 11/Jun/2019).

4. Golde CM, Walker GE, Jones L, Bueschel AC, Hutchings P. The formation of scholars: Rethinking doctoral education for the twentyfirst century. San Francisco: Jossey-Bass; 2008.

5. Organisation for Economic Co-operation and Development. Post-graduate education in the 1980s. Paris: Organisation for Economic Cooperation and Development; 1987.

6. Sadlak J. Studies on higher education. Doctoral studies and qualifications in Europe and the United States: status and prospects. Bucharest: United Nations Educational, Scientific and Cultural Organization; 2004.

7. Ives G, Rowley B. Supervisor selection or allocation and continuity of supervision: $\mathrm{PhD}$ students' progress and outcomes. Studies in Higher Education 2005; 30:535-55.

8. European University Association. Universities outline future priorities for improving the quality of doctoral education in Europe. http://www.eua.be/fileadmin/user_upload/ files/Press/CDEpostconfdef.pdf (acessado em 10/Jun/2019).
9. Halse C, Malfroy J. Retheorizing doctoral supervision as professional work. Studies in Higher Education 2010; 35:79-92.

10. Lindén J, Ohlin M, Brodin EM. Mentorship, supervision and learning experience in $\mathrm{PhD}$ education. Studies in Higher Education 2013; 38:630-62.

11. Malfroy J. Doctoral supervision, workplace research and changing pedagogic practices. Higher Education Research \& Development $2005 ; 24: 165-78$

12. Kamler B. Rethinking doctoral publication practices: writing from and beyond the thesis. Studies in Higher Education 2008; 33:283-94.

13. Kritsonis WA, Green WR. Functions of the Doctoral Dissertation advisor. Focus on Colleges, Universities and Schools 2008; 2:1-5.

14. Diniz D. Carta de uma orientadora: o primeiro projeto de pesquisa. Brasília: Letras Livres; 2012.

15. Pearson M, Kayrooz C. Enabling critical reflection on research supervisory practice. International Journal for Academic Development 2004; 1:99-116.

16. Lee A. How are doctoral students supervised? Concepts of doctoral research supervision. Studies in Higher Education 2008; 33:267-81.

17. Vilkinas T. An exploratory study of the supervision of $\mathrm{PhD} /$ research students' theses. Innovative Higher Education 2011; 32:297-11.

18. Eu confesso. Blog: odeio meu orientador, 2018. https://www.euconfesso.com/confiss ao-100245.html (acessado em 15/Jul/2019).

19. Kleijn RAM, Mainhard MT, Meijer PC, Brekelmans M, Pilot A. Master's thesis projects: student perceptions of supervisor feedback. Assessment \& Evaluation in Higher Education 2013; 38:1012-26.
Recebido em 17/Jul/2019

Versão final reapresentada em 25/Jul/2019

Aprovado em 30/Jul/2019 